\title{
BMJ
}

\section{Effects of glucosamine, chondroitin, or placebo in patients with osteoarthritis of hip or knee: network meta-analysis}

\author{
Simon Wandel, research fellow, ${ }^{1,2}$ Peter Jüni, professor and head of division, ${ }^{1,2}$ Britta Tendal, research fellow, ${ }^{3}$ \\ Eveline Nüesch, research fellow, ${ }^{1,2}$ Peter M Villiger, director, ${ }^{4}$ Nicky J Welton, senior research fellow, ${ }^{5}$ Stephan \\ Reichenbach, senior research fellow, ${ }^{1,4}$ Sven Trelle, senior research fellow ${ }^{1,2}$
}

\section{ABSTRACT}

Objective To determine the effect of glucosamine, chondroitin, or the two in combination on joint pain and on radiological progression of disease in osteoarthritis of the hip or knee.

Design Network meta-analysis. Direct comparisons within trials were combined with indirect evidence from other trials by using a Bayesian model that allowed the synthesis of multiple time points.

Main outcome measure Pain intensity. Secondary outcome was change in minimal width of joint space. The minimal clinically important difference between preparations and placebo was prespecified at $-0.9 \mathrm{~cm}$ on a $10 \mathrm{~cm}$ visual analogue scale.

Data sources Electronic databases and conference proceedings from inception to June 2009, expert contact, relevant websites.

Eligibility criteria for selecting studies Large scale randomised controlled trials in more than 200 patients with osteoarthritis of the knee or hip that compared glucosamine, chondroitin, or their combination with placebo or head to head.

Results 10 trials in 3803 patients were included. On a 10 $\mathrm{cm}$ visual analogue scale the overall difference in pain intensity compared with placebo was $-0.4 \mathrm{~cm}(95 \%$ credible interval -0.7 to $-0.1 \mathrm{~cm}$ ) for glucosamine, $-0.3 \mathrm{~cm}$ $(-0.7$ to $0.0 \mathrm{~cm})$ for chondroitin, and $-0.5 \mathrm{~cm}(-0.9$ to 0.0 $\mathrm{cm}$ ) for the combination. For none of the estimates did the $95 \%$ credible intervals cross the boundary of the minimal clinically important difference. Industry independent trials showed smaller effects than commercially funded trials ( $P=0.02$ for interaction). The differences in changes in minimal width of joint space were all minute, with $95 \%$ credible intervals overlapping zero.

Conclusions Compared with placebo, glucosamine, chondroitin, and their combination do not reduce joint pain or have an impact on narrowing of joint space. Health authorities and health insurers should not cover the costs of these preparations, and new prescriptions to patients who have not received treatment should be discouraged.

\section{INTRODUCTION}

Osteoarthritis of the hip or knee is a chronic condition mostly treated with analgesics and non-steroidal anti- inflammatory drugs, but these drugs can cause serious gastrointestinal and cardiovascular adverse events, especially with long term use. ${ }^{12}$ Disease modifying agents that not only reduce joint pain but also slow the progression of the condition would be desirable. Throughout the world for the past 10 years, the cartilage constituents chondroitin and glucosamine have been increasingly recommended in guidelines, prescribed by general practitioners and rheumatologists, and used by patients as over the counter medications to modify the clinical and radiological course of the condition. ${ }^{3}$ Global sales of glucosamine supplements reached almost $\$ 2 \mathrm{bn}(£ 1.3 \mathrm{bn}, € 0.8 \mathrm{bn})$ in 2008 , which represents an increase of about $60 \%$ compared with 2003 , with a forecasted continued growth through 2013 reaching $\$ 2.3 \mathrm{bn}$. $^{4}$ The oral administration of cartilage constituents in patients with osteoarthritis is thought to make up for the apparent cartilage loss in affected joints. Chondroitin is a highly hydrophilic, gel forming polysaccharide macromolecule. Its hydrocolloid properties convey much of the compressive resistance of cartilage. Glucosamine is an amino sugar that is a building block for the glycosaminoglycans that are part of the structure of cartilage. Ingested chondroitin and glucosamine are both partially absorbed in the intestine, and it has been suggested that some of the ingested amount reaches the joints. ${ }^{5-7}$

Results from randomised trials about the effectiveness of chondroitin and glucosamine are conflicting. ${ }^{8-11}$ Trials that have reported large effects on joint pain were often hampered by poor study quality and small sample sizes, ${ }^{9-12}$ whereas large methodologically sound trials often found only small or no effects. ${ }^{101113}$

Bayesian approaches towards network meta-analyses allow a unified, coherent analysis of data recorded at multiple time points in randomised trials that compare either of these preparations with placebo or head to head. ${ }^{14-16}$ The approaches fully respect randomisation, account for the correlation of multiple observations within the same trial, and allow the estimation of the relative effectiveness of the different preparations and their combination. We performed a systematic review with network meta-analysis including data from large methodologically sound 
randomised trials at multiple follow-up times to determine the effect of these preparations on joint pain and on radiological progression of disease.

\section{METHODS}

\section{Literature search}

We searched the Cochrane Controlled Trials Register, Medline, Embase, and CINAHL (from inception to June 2010) using a combination of keywords and text words related to osteoarthritis; these were combined with generic and trade names of the various preparations plus a validated filter for controlled clinical trials. ${ }^{17} \mathrm{We}$ also retrieved reports citing relevant articles via Science Citation Index (1981-2008). In addition, we manually searched conference proceedings and text books, screened reference lists of all obtained papers, and contacted content experts.

\section{Study selection}

We included randomised trials with an average of at least 100 patients with knee or hip osteoarthritis per arm. ${ }^{18}$ Trials compared chondroitin sulphate, glucosamine sulphate, glucosamine hydrochloride, or the combination of any two with placebo or head to head. A sample size of $2 \times 100$ patients will yield more than $80 \%$ power to detect a small to moderate effect size of -0.40 at a two sided $\mathrm{P}=0.05$, which corresponds to a difference of $1 \mathrm{~cm}$ on a $10 \mathrm{~cm}$ visual analogue scale between the experimental and control intervention. Two of four reviewers (BT, EN, SR, ST) evaluated reports independently for eligibility. They excluded trial arms with sub-therapeutic doses $(<800 \mathrm{mg} /$ day of chondroitin and $<1500 \mathrm{mg} /$ day of glucosamine, in accordance with doses licensed in Europe). Disagreements were resolved by consensus.

\section{Outcome measures}

The prespecified primary outcome was absolute pain intensity reported in any of nine time windows organised in increments of three months (up to 3 months, 6 , $9,12,15,18,21$ months, and 22 months or more). If more than one time point was reported in a window, we extracted data nearest to the longest follow-up time included in that window; for the window covering 22 months or more, we extracted the follow-up closest to 24 months. When an article provided data on more than one pain scale, we referred to a previously described hierarchy of pain related outcomes and extracted the outcome that was highest on this list. ${ }^{9}$ Global pain took precedence over pain on walking and pain subscores on the Western Ontario and McMaster Universities (WOMAC) arthritis index. If a trial report provided data on both-for example, global pain scores and WOMAC pain subscores-we recorded only data on global pain scores. Secondary outcomes were changes in the minimum radiographic joint space between baseline and the end of treatment, the number of individuals withdrawn or who dropped out because of an adverse event, and the number of patients experiencing any adverse event.

\section{Quality assessment}

Two of the four reviewers independently assessed concealment of allocation, blinding, and adequacy of analyses. ${ }^{19}$ Concealment of allocation was considered adequate if the investigators responsible for the selection of patients did not know before allocation which treatment was next in line (central randomisation, sealed, opaque, sequentially numbered assignment envelopes, coded drug packs, etc). Any procedures based on predictable generation of allocation sequences, and potentially transparent attempts to conceal allocation, such as non-opaque envelopes, were considered inadequate. We extracted the number of patients initially randomised and the number of patients analysed per group at each time point to distinguish between trials that had included all randomised patients in the analysis (intention to treat analysis) and trials that had not. Finally, we determined whether experimental preparations had undergone quality control - that is, if either a formally approved preparation was used or pharmacological laboratory analysis confirmed the content of the preparation. Disagreements were resolved by consensus.

\section{Data collection}

Two of the four reviewers used a standardised form to extract in duplicate data on publication status, trial design, patients' characteristics, treatment regimens, outcome modalities, and funding. Results of pain, joint space narrowing, and adverse events were extracted by one reviewer (ST) and cross checked by another (PJ). When necessary, means and measures of dispersion were approximated from figures in the reports.

\section{Statistical analysis}

We used an extension of multivariable Bayesian hierarchical random effects models for mixed multiple treatment comparisons with minimally informative prior distributions. ${ }^{2021}$ It fully preserves the comparison of randomised treatments within each trial while combining all available comparisons between treatments and accounts for multiple comparisons within a trial when there are more than two treatment arms. ${ }^{22}$ For the analysis of effect sizes of pain, the model included random effects at the level of trials and time points. It accounted for the correlation of outcome data reported at different time points within a trial and allowed the estimation of the variance of treat ment effects between trials $\left(\tau^{2}\right)$. Effect sizes were calculated by dividing the differences in mean values between treatment groups in a time window by the median pooled standard deviation (SD) observed across all time points in a trial. ${ }^{23}$ If SDs were not provided, we calculated them from standard errors or confidence intervals as described elsewhere. ${ }^{1024}$ An effect size of -0.20 SD units suggests an overlap in the distributions of reported pain scores in the experimental group with pain scores in placebo group in $85 \%$ and can be considered a small difference between experimental and control group. ${ }^{923}$ An effect size of -0.50 
indicates an overlap in about $67 \%$ and can be considered a moderate difference, whereas -0.80 suggests an overlap in $53 \%$ and is considered a large difference. ${ }^{923}$

To allow intuitive interpretation of pooled effects, we back transformed effect sizes to differences on a $10 \mathrm{~cm}$ visual analogue scale on the basis of a median pooled SD of $2.5 \mathrm{~cm}$ found in large scale osteoarthritis trials that assessed pain on a $10 \mathrm{~cm}$ visual analogue scale. ${ }^{12}$ We prespecified a minimal clinically important difference of $0.37 \mathrm{SD}$ units, corresponding to $0.9 \mathrm{~cm}$ on a $10 \mathrm{~cm}$ visual analogue scale. This was based on the median minimal clinically important difference found in recent studies in patients with osteoarthritis. ${ }^{25-28} \mathrm{As}$ the analysis of changes of minimum radiographic joint space did not include multiple time points, the model used for this outcome included only a random effect at the level of trials. To achieve comparability of the magnitude of effects on joint space and on pain and distinguish between small, moderate, and large treatment effects, we expressed differences in the width of the joint space as effect sizes, dividing the pooled estimates in millimetres by the median pooled SD of $1.2 \mathrm{~mm}$ found in included trials.

Whenever possible, we used results of intention to treat analysis including all randomised patients. ${ }^{12}$ Pooled effect sizes were estimated from the median of the posterior distribution. A negative effect size indicates a benefit of the experimental intervention. Corresponding 95\% credible intervals were estimated from the 2.5th and 97.5th centiles of the posterior distribution. ${ }^{15}$ In the presence of minimally informative priors, credible intervals can be interpreted in a similar way to conventional confidence intervals. To determine whether the variation of treatment effects over time was over and above what would be expected by chance, we calculated a $\mathrm{P}$ value for heterogeneity across time points of follow-up. ${ }^{29}$ The $\mathrm{P}$ value was derived from the proportion of observations of the posterior distribution of the variance observed across time points within trials smaller than or equal to the variance within trials typically found in large osteoarthritis trials ( 0.01 for an effect size scale, 0.0625 for a $10 \mathrm{~cm}$ visual analogue scale).

To explore possible time trends, we included a linear term for time as a covariate in the analyses. We then included characteristics of the trials as covariates in the network meta-analysis to estimate effects according to concealment of allocation; intention to treat analysis; high methodological quality defined as adequate concealment of allocation, adequate blinding of patients, and the presence of an intention to treat analysis; source of funding (industry independent $v$ other); type of glucosamine used (sulphate $v$ hydrochlorides); quality control of preparations; and type of joint affected (knee $v$ hip). P values for interaction between trial characteristics and treatment effect were derived from the posterior distribution of covariates and can be interpreted in the same way as a traditional $\mathrm{P}$ value for interaction. ${ }^{30}$

Heterogeneity between trials was estimated from the median variance between trials $\left(\tau^{2}\right)$ observed in the posterior distribution with the following prior distributions: a gamma distribution for heterogeneity between trials $\left(1 / \tau^{2}\right.$ gamma $\left.(0.001,0.001) \mathrm{I}(0,2000)\right)$, and a uniform distribution for heterogeneity between time points ( $\tau$ unif $(0,50))$. In a sensitivity analysis we also used a uniform prior for the heterogeneity between trials. The consistency of the network was determined by use of inconsistency factors: the estimated difference between the effect size from direct comparisons within randomised trials and the effect size from indirect comparisons between randomised trials with one intervention in common. ${ }^{31}$ Estimates of variation and consistency are based on back transformations to differences on a $10 \mathrm{~cm}$ visual analogue scale. Goodness of $\mathrm{t}$ was assessed with Q-Q plots.

Finally, we performed pairwise meta-analyses with random effects at the level of trials and time points, as well as a simpler network meta-analysis including only one treatment effect per trial (absolute pain intensity at the longest follow-up available). Convergence of Markov chains was deemed to be achieved if plots of the Gelman-Rubin statistics indicated that widths of pooled runs and individual runs stabilised around the same value and their ratio around one. ${ }^{32}$ Accordingly, all analyses are based on 150000 iterations, of which the first 50000 were discarded as burn-in period. We used Stata (Stata Statistical Software: release 10; StataCorp LP 2005, College Station, TX) and WinBUGS (version 1.4; MRC Biostatistics Unit 2007, Cambridge, $\mathrm{UK})$ for all analyses.

\section{RESULTS}

Out of 58 potentially eligible reports, 12 reports describing 10 trials met our inclusion criteria and were included in the network meta-analysis. ${ }^{133-43}$ All trials were published as full journal articles. For one trial two publications were included ${ }^{1342}$; for another trial $^{43}$ additional data were provided in an electronic rapid response. ${ }^{40}$

\section{Study characteristics}

The 10 included trials had randomly allocated a total of 3803 patients to either of the experimental interventions or placebo. Figure 1 shows the network of interventions. Five trials (1104 randomised patients) compared glucosamine sulphate with placebo. ${ }^{33-353941}$ In another placebo controlled trial (205 patients), the investigators were forced to change from glucosamine sulphate to glucosamine hydrochloride after $80 \%$ of the patients had been treated with glucosamine sulphate because the manufacturer of glucosamine sulphate declined to supply matching placebos. ${ }^{36}$ Three trials (1229 patients) compared chondroitin sulphate with placebo, ${ }^{373843}$ and one trial (1265 patients) compared glucosamine hydrochloride, chondroitin sulphate, and their combination with placebo. ${ }^{13}$ Tables 1 and 2 show the characteristics of trials.

Six trials described adequate concealment of allocation, ${ }^{133536394143}$ nine trials reported adequate blinding of patients, and in one trial ${ }^{34}$ it was unclear. Seven trials performed an intention to treat 
Table 1|Characteristics of identified randomised trials of glucosamine or chondroitin for osteoarthritis of hip or knee

\begin{tabular}{|c|c|c|c|c|c|c|c|c|c|c|c|c|}
\hline Study & $\begin{array}{c}\text { Quality } \\
\text { controlled } \\
\text { preparation }\end{array}$ & $\begin{array}{c}\text { Treatment } \\
\text { duration } \\
\text { (weeks) }\end{array}$ & $\begin{array}{l}\text { Conceal- } \\
\text { ment } \\
\text { adequate }\end{array}$ & $\begin{array}{l}\text { Patient } \\
\text { blinding } \\
\text { adequate }\end{array}$ & $\begin{array}{c}\text { ITT } \\
\text { per- } \\
\text { formed }\end{array}$ & $\begin{array}{l}\text { Mean } \\
\text { age } \\
\text { (years) }\end{array}$ & $\begin{array}{c}\% \\
\text { women }\end{array}$ & $\begin{array}{c}\text { Symptom } \\
\text { duration } \\
\text { (years) }\end{array}$ & $\begin{array}{l}\text { Joint } \\
\text { affected }\end{array}$ & $\begin{array}{l}\text { Pain outcome } \\
\text { extracted }\end{array}$ & Funding Source & $\begin{array}{c}\text { Time point } \\
\text { extracted } \\
\text { (months) }\end{array}$ \\
\hline \multicolumn{13}{|c|}{ Glucosamine $v$ placebo } \\
\hline Noack $1994^{33}$ & Yes & $1-4$ & Unclear & Yes & No & NA & NA & $\geq 0.5$ & Knee & Lequesne & Rottapharm & 1 \\
\hline Reginster $2001^{34}$ & Yes & $1-156$ & Unclear & Unclear & Yes & 66 & 76 & 7.8 & Knee & $\begin{array}{l}\text { WOMAC pain } \\
\text { subscale }\end{array}$ & Rottapharm & 36 \\
\hline Pavelka $2002^{35}$ & Yes & $1-156$ & Yes & Yes & Yes & 62 & 78 & 10.6 & Knee & Lequesne & Rottapharm & $3,6,(\ldots), 36$ \\
\hline $\begin{array}{l}\text { McAlindon } \\
2004^{36}\end{array}$ & Yes & $1-12$ & Yes & Yes & Yes & 61 & 64 & NA & Knee & $\begin{array}{l}\text { WOMAC pain } \\
\text { subscale }\end{array}$ & $\begin{array}{l}\text { NLM and Arthritis } \\
\text { Foundation }\end{array}$ & 3 \\
\hline $\begin{array}{l}\text { Herrero- } \\
\text { Beaumont } \\
2007^{39}\end{array}$ & Yes & $1-26$ & Yes & Yes & No & 64 & 86 & 10.4 & Knee & Lequesne & Rottapharm & 3,6 \\
\hline $\begin{array}{l}\text { Rozendaal } \\
2008^{41}\end{array}$ & Unclear & $1-104$ & Yes & Yes & Yes & 64 & 69 & $>3^{*}$ & Hip & Global pain & $\begin{array}{l}\text { Erasmus Medical } \\
\text { Center } \\
\text { Breedtestrategie }\end{array}$ & $3,6,(\ldots), 24$ \\
\hline \multicolumn{13}{|c|}{ Chondroitin v placebo } \\
\hline Michel $2005^{37}$ & Yes & $1-103$ & Unclear & Yes & Yes & 63 & 52 & NA & Knee & $\begin{array}{l}\text { WOMAC pain } \\
\text { subscale }\end{array}$ & IBSA & 24 \\
\hline Mazières $2007^{38}$ & Unclear & $1-26$ & Unclear & Yes & Unclear & 61 & 62 & NA & Hip or knee & Pain on activity & Pierre Fabre & $3,6,9$ \\
\hline Kahan $2009^{43}$ & Yes & $1-132$ & Yes & Yes & Yes & 62 & 68 & 6.5 & Knee & Global pain & IBSA & $3,6,(\ldots), 24$ \\
\hline \multicolumn{13}{|c|}{ Glucosamine $v$ chondroitin $v$ glucosamine and chondroitin combined $v$ placebo } \\
\hline Clegg $2006^{13}$ & Yes & $1-24$ & Yes & Yes & Yes & 58 & 27 & 9.6 & Knee & $\begin{array}{l}\text { WOMAC pain } \\
\text { subscale }\end{array}$ & $\mathrm{NIH}$ & 6 \\
\hline
\end{tabular}

NA=not available; NIH=US National Institute of Health; NLM=US National Library of Medicine.

${ }^{*}$ Duration $>3$ years for more than half of patients.

analysis. ${ }^{1334-374143}$ Eight trials included patients with osteoarthritis of the knee only, ${ }^{133-373943}$ one trial included patients with osteoarthritis of the hip or knee ${ }^{38}$ and one trial included patients with osteoarthritis of the hip only. ${ }^{41}$ All except three trials ${ }^{133641}$ were funded by manufacturers of supplements. In eight trials, experimental preparations had undergone quality control to ensure adequate concentrations of glucosamine or chondroitin, and in two trials ${ }^{3841}$ it was unclear. The average age of patients was 58-66 (median 62 ), and the percentage of women ranged from $27 \%$ to $86 \%$ (median 68\%). The average duration of symptoms ranged from a minimum of six months to more than 10 years. All treatments were administered on consecutive days in all trials. Duration of follow-up varied substantially between trials, from one month ${ }^{33}$ to 36 months, ${ }^{3435}$ and the number of follow-up visits from one $\mathrm{e}^{13333437}$ to $12^{35}$ (table 1 ).

\section{Effects on joint pain}

All trials contributed to the network meta-analysis of pain related outcomes (see appendix 1 on bmj.com). Figure 2 presents pooled estimates across different time points. The variation across time points was not over and above what would be expected by chance $\left(\tau^{2}=0.04\right.$ for variation across time points on a $10 \mathrm{~cm}$ visual analogue scale, $\mathrm{P}=0.93$ for interaction between treatment effect and time). The overall difference in pain intensity versus placebo based on a summary of all time points was $-0.4 \mathrm{~cm}(95 \%$ credible interval -0.7 to $-0.1 \mathrm{~cm}$ ) on a $10 \mathrm{~cm}$ visual analogue scale for glucosamine, $-0.3 \mathrm{~cm}(-0.7$ to $0.0 \mathrm{~cm})$ for chondroitin, and $-0.5 \mathrm{~cm}(-0.9$ to $0.0 \mathrm{~cm})$ for the combination of glucosamine and chondroitin. Corresponding effect sizes were $-0.17(-0.28$ to -0.05$)$ for glucosamine, -0.13 $(-0.27$ to 0.00$)$ for chondroitin, and $-0.19(-0.37$ to $0.00)$ for the combination. Heterogeneity between trials was low $\left(\tau^{2}=0.04\right.$ for heterogeneity between trials on a $10 \mathrm{~cm}$ visual analogue scale), there was no evidence for inconsistency (inconsistency factor $0.2 \mathrm{~cm}$, -0.7 to $1.1, \mathrm{P}=0.63)$, and the goodness of fit of the model to the data was excellent (data available on request). Results from the primary network meta-analysis were concordant with a model including a linear term for time, conventional meta-analyses of direct comparisons, a network meta-analysis, which included only one time point for pain intensity at the end of follow-up, and an analysis with a different prior

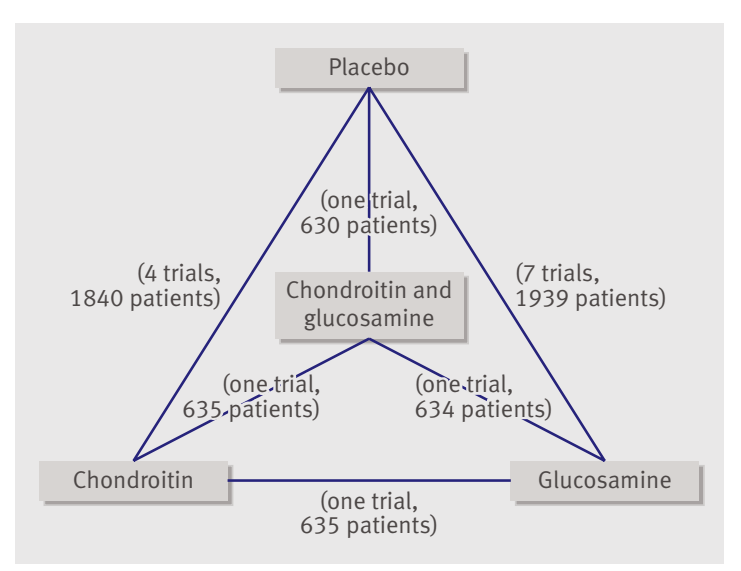

Fig 1 | Structure of network formed by interventions and their direct comparisons. Numbers of trials and patients do not add up to numbers reported in table 2 because of multi-arm trial by Clegg et $\mathrm{al}^{13}$ 
Table 2 |Characteristics of identified randomised trials of glucosamine or chondroitin for osteoarthritis of hip or knee by treatment arm

\begin{tabular}{|c|c|c|c|c|}
\hline Trial & Treatment (daily dose) & $\begin{array}{l}\text { Patients } \\
\text { randomised }\end{array}$ & $\begin{array}{l}\text { Patients analysed } \\
\text { for pain }\end{array}$ & $\begin{array}{l}\text { Patients analysed } \\
\text { for joint space }\end{array}$ \\
\hline \multicolumn{5}{|c|}{ Glucosamine $v$ placebo } \\
\hline Noack $1994^{33}$ & Glucosamine sulphate $(1500 \mathrm{mg}) /$ placebo & $126 / 126$ & $120 / 121$ & NA \\
\hline Reginster $2001^{34}$ & Glucosamine sulphate $(1500 \mathrm{mg}) /$ placebo & $106 / 106$ & $106 / 106$ & $106 / 106$ \\
\hline Pavelka $2002^{35}$ & Glucosamine sulphate $(1500 \mathrm{mg}) /$ placebo & $101 / 101$ & $101 / 101$ & $101 / 101$ \\
\hline McAlindon $2004^{36}$ & $\begin{array}{l}\text { Glucosamine sulphate }(1500 \mathrm{mg}) \text { or glucosamine } \\
\text { hydrochloride }(1500 \mathrm{mg}) / \text { placebo }\end{array}$ & $101 / 104$ & $101 / 104$ & NA \\
\hline $\begin{array}{l}\text { Herrero-Beaumont } \\
2007^{39}\end{array}$ & Glucosamine $(1500 \mathrm{mg}) /$ placebo & $109 / 107$ & $106 / 104$ & NA \\
\hline Rozendaal $2008^{41}$ & Glucosamine $(1500 \mathrm{mg}) /$ placebo & $111 / 111$ & $111 / 111$ & $111 / 111$ \\
\hline \multicolumn{5}{|c|}{ Chondroitin $v$ placebo } \\
\hline Michel $2005^{37}$ & Chondroitin sulphate $(800 \mathrm{mg}) /$ placebo & $150 / 150$ & $150 / 150$ & $150 / 150$ \\
\hline Mazières $2007^{38}$ & Chondroitin sulphate $(1000 \mathrm{mg}) /$ placebo & NA & $153 / 154$ & NA \\
\hline Kahan $2009^{43}$ & Chondroitin sulphate $(800 \mathrm{mg}) /$ placebo & $309 / 313$ & $309 / 313$ & $309 / 313$ \\
\hline \multicolumn{5}{|c|}{ Glucosamine $v$ chondroitin $v$ glucosamine and chondroitin combined $v$ placebo } \\
\hline Clegg $2006^{13}$ & $\begin{array}{l}\text { Glucosamine hydrochloride }(1500 \mathrm{mg}) / \\
\text { chondroitin sulphate }(1200 \mathrm{mg}) / \text { glucosamine } \\
\text { hydrochloride }(1500 \mathrm{mg}) \text { and chondroitin sulphate } \\
(1200 \mathrm{mg}) / \text { placebo }\end{array}$ & $317 / 318 / 317 / 313$ & $317 / 318 / 317 / 313$ & $77 / 71 / 59 / 70$ \\
\hline
\end{tabular}

distribution for the heterogeneity between trials (see appendix 2 on bmj.com).

Figure 3 shows the results from stratified analyses. Estimates comparing supplements with placebo depended to some extent on the quality of the trials, the presence or absence of quality control measures for preparations, the type of study joint, and the type of glucosamine salt used, but tests for interaction were all negative for these variables $(\mathrm{P} \geq 0.20$ for interaction). The estimated differences between supplements and placebo, however, were, on average, $0.5 \mathrm{~cm}(0.1$ to $0.9 \mathrm{~cm}$ ) less pronounced in industry independent trials compared with industry sponsored trials $(\mathrm{P}=0.02$ for interaction).

\section{Effects on radiological joint space}

Six trials reported changes in width of joint space. $^{34353741-43}$ The network meta-analysis of differences in changes in minimal joint space narrowing at the end of the treatment period showed minute effects for all preparations compared with placebo. The difference was $-0.2 \mathrm{~mm}(-0.3$ to $0.0 \mathrm{~mm})$ in favour of glucosamine, $-0.1 \mathrm{~mm}(-0.3$ to $0.1 \mathrm{~mm})$ in favour of chondroitin, and $0.0 \mathrm{~mm}(-0.2$ to $0.2 \mathrm{~mm})$ for the combination, which corresponded to effect sizes of -0.16 $(-0.25$ to 0.0$),-0.08$ ( -0.25 to 0.08$)$, and 0.00 ( -0.16 to $0.16)$. Heterogeneity between trials was low $\left(\tau^{2}=0.02\right)$, there was no evidence for inconsistency (inconsistency factor $-0.1 \mathrm{~mm},-0.6$ to $0.4 \mathrm{~mm} ; \mathrm{P}=0.54)$, and the goodness of fit of the model to the data was excellent.

\section{Safety}

Five trials reported on adverse events, ${ }^{33-353841}$ all 10 reported withdrawals or drop-outs because of adverse events, and three reported serious adverse events. ${ }^{33841}$ The odds ratios of adverse events compared with placebo were 0.94 (0.59 to 1.47) for glucosamine and 0.99 (0.49 to 2.00) for chondroitin; no data were available on adverse events overall for the combination. The odds ratios for withdrawals or drop-outs because of adverse events were 0.99 (0.61 to 1.50$)$ for glucosamine, 0.92 ( 0.56 to 1.51$)$ for chondroitin, and $0.90(0.43$ to 1.85$)$ for the combination. Heterogeneity between trials was low for both outcomes, with $\tau^{2}$ of 0.02 and 0.03 , respectively. We could estimate inconsistency only for drop-outs because of adverse events, with some evidence of inconsistency (ratio of relative risks $0.54,0.19$ to $1.46, \mathrm{P}=0.22$ for inconsistency).

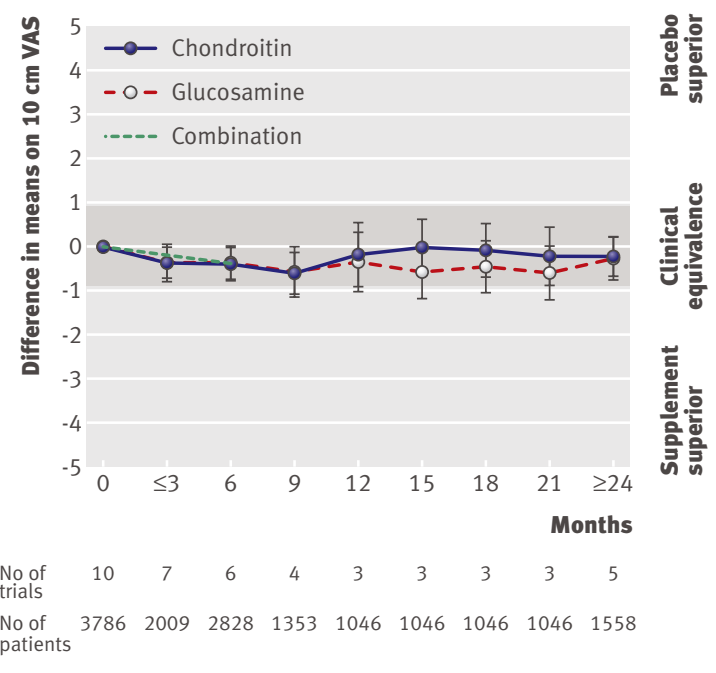

Fig 2 | Differences in pain intensity measured on visual analogue scale (VAS) between experimental interventions and placebo over time. Shading represents area of clinical equivalence. Negative values indicate benefit of experimental interventions compared with placebo 


\section{DISCUSSION}

\section{Principal findings}

Our network meta-analysis of all 10 available large scale patient blind randomised trials in 3803 patients with knee or hip osteoarthritis showed no clinically relevant effect of chondroitin, glucosamine, or their combination on perceived joint pain. Despite abundant statistical power, none of the pooled estimates crossed the pre-specified boundary of a minimal clinically important difference of $-0.9 \mathrm{~cm}$ on a $10 \mathrm{~cm}$ visual analogue scale at any of the recorded time points. At some time points the $95 \%$ credible interval crossed this boundary (see fig 3), which could mean that we cannot exclude a relevant effect at such time points. The overall estimates, which combine effects over different time points, were precise, however, and the lower end of their credible intervals did not cross the pre-specified boundary. These estimates should be considered most valid in view of the negative test of interaction of treatment effects by time $(\mathrm{P}=0.93)$, which indicates that the observed variation over different time points is not over and above what would be expected by chance alone.

The upper limit of the $95 \%$ credible interval of the overall pooled estimate of glucosamine versus placebo and chondroitin versus placebo did not overlap the line of no effect, which suggests that a traditional $\mathrm{P}$ value for this comparison would be significant at the conventional 5\% level. Statistical significance should not, however, be confused with clinical relevance. With the observed differences in pain intensity of 0.3 to $0.5 \mathrm{~cm}$ between supplements and placebo on a $10 \mathrm{~cm}$ visual analogue scale, the range and distribution of pain scores in patients receiving supplements and placebo are near identical, ${ }^{923}$ and it would be impossible, based on the reported pain intensity at the end of a trial, to determine whether a patient was allocated to a supplement or to placebo.

In stratified analyses, we found that estimates comparing supplements with placebo depended to some extent on the quality of the trials, the presence or absence of quality control measures for preparations, the joint studied, and the type of glucosamine salt used, but tests for interaction were all negative for these variables $(\mathrm{P} \geq 0.20$ for interaction). On average, the estimated differences between supplements and placebo were $0.5 \mathrm{~cm}$ less pronounced in industry independent trials compared with industry sponsored trials, and estimated treatment effects in industry independent trials were minute to zero and by no means clinically relevant (see fig 2). The effects on minimal width of
Glucosamine $v$ placebo

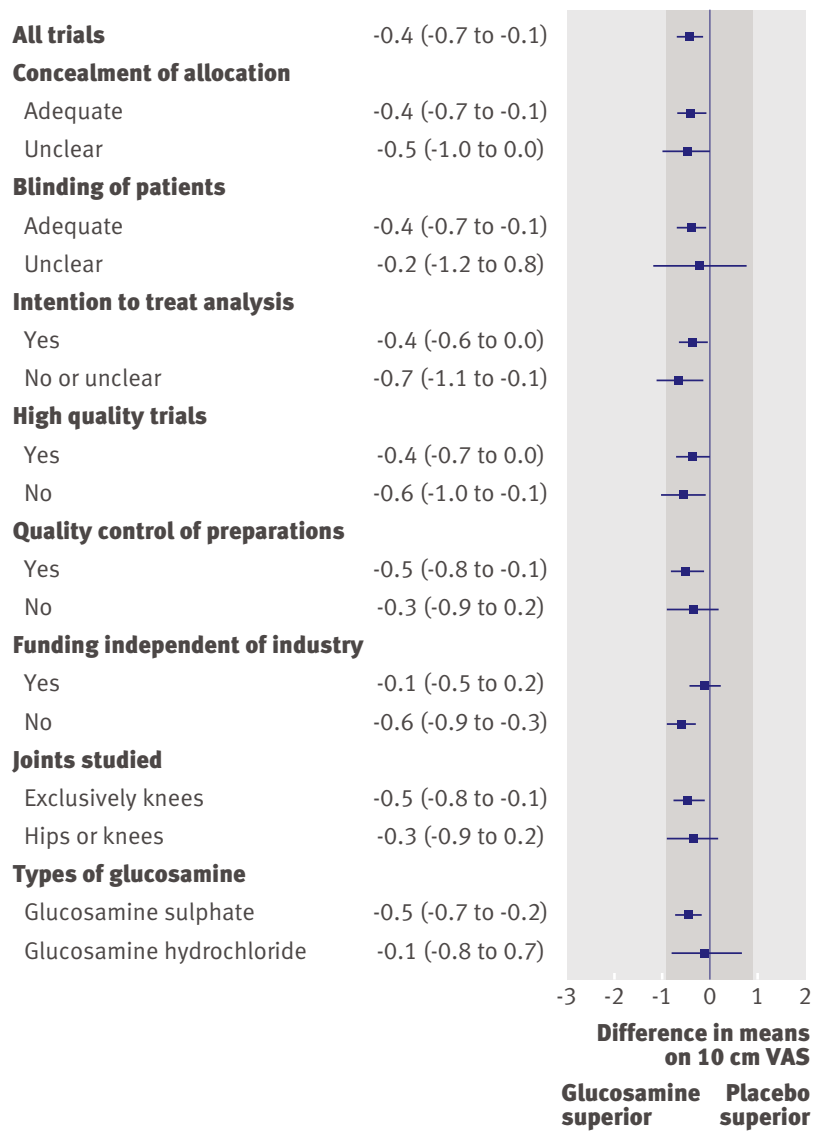

Chondroitin v placebo

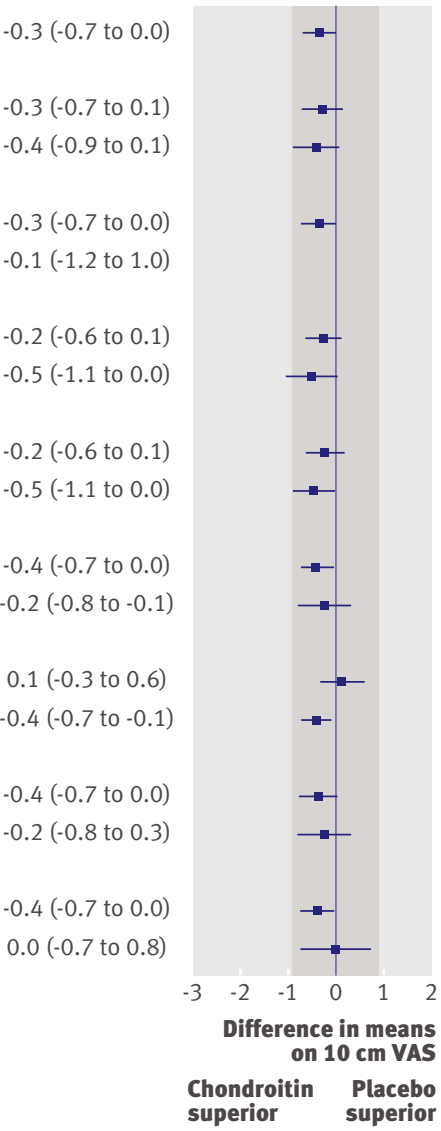

Combination v placebo

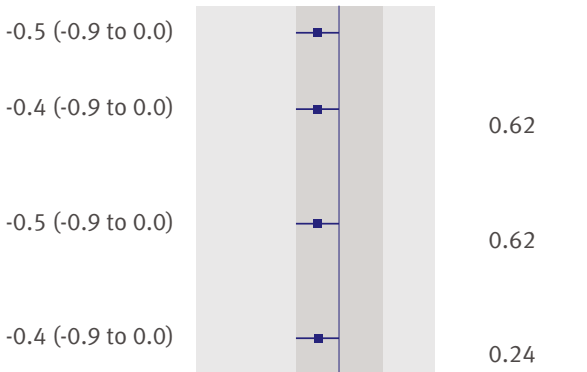

$-0.4(-0.9$ to 0.0$)$

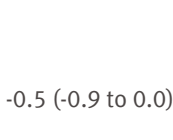

$-0.3(-0.7$ to 0.2$)$

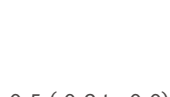

$-0.5(-0.9$ to 0.0$)$

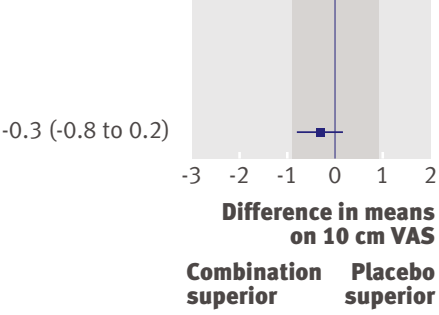

P for interaction

Fig 3 | Stratified analyses of differences ( $95 \%$ confidence interval) on $10 \mathrm{~cm}$ visual analogue scale (VAS) in pain intensity between experimental interventions and placebo. Shading represents area of clinical equivalence. Negative values indicate benefit of experimental interventions compared with placebo 
joint space were small, again clinically irrelevant, andwith credible intervals overlapping the line of no effect -non-significant at the conventional $\alpha$ level of $5 \%$.

\section{Strengths and weaknesses}

Our network meta-analysis integrated evidence from direct and indirect comparisons while fully preserving randomisation. It enabled us to simultaneously analyse effect sizes reported at different follow-up times in a single model and to estimate the overall effect of preparations irrespective of the duration of follow-up while fully accounting for potential variation across time points and for the correlation of estimates within a trial. Consequently, estimates in our analysis were more precise than the pairwise meta-analyses or the network meta-analysis with only pain intensity at the end of follow-up (see appendix 2 on bmj.com).

We performed an extensive literature search, ${ }^{44}$ which makes it unlikely that we missed any relevant trial. Trial selection and data extraction including quality assessment were done independently by two authors to minimise bias and transcription errors. ${ }^{45}$ Components used for quality assessment are validated and reported to be associated with bias. ${ }^{12} 1946$ In line with our pre-specified inclusion criteria, the trials in our network were large and of satisfactory methodological quality.

As with conventional meta-analyses, some will argue that we have not compared like with like. Our model, however, was based on relative treatment effects (differences between groups expressed as effect sizes ${ }^{23}$ ), and variations in patients' characteristics between trials are fully accounted for in the analysis by maintaining randomised comparisons within each trial. Network meta-analysis makes similar assumptions to standard metaanalysis of direct comparisons within trials but requires that these assumptions hold over the entire set of trials in the network - that is, for the indirect comparisons also. In addition, our model assumes that relative treatment effects comparing two interventions in different trials are from the same common distribution. The smaller the heterogeneity between trials, and the smaller the inconsistency between direct randomised comparisons and indirect comparisons, the more likely these assumptions hold. The heterogeneity between trials in our analysis was near zero and the upper credible interval for the $\tau^{2}$ estimate was 0.24 on a $10 \mathrm{~cm}$ visual analogue scale (the maximum $\tau$ of the underlying distribution of treatment effects compatible with the credible interval would be $0.5 \mathrm{~cm})$. In addition, we investigated potential sources of variation in the network by including characteristics of trials as covariates in the analysis of the primary outcome. Taken together, results of these analyses make it likely that relative treatment effects originate from one common distribution and confirm one of our key assumptions. As with heterogeneity between trials, inconsistency between direct and indirect comparisons was also near zero (inconsistency factor $0.2 \mathrm{~cm}$ ). Although we cannot rule out clinically relevant inconsistency (the upper credible interval for the inconsistency factor crossed the pre-specified threshold for a clinically relevant effect at $0.9 \mathrm{~cm}$ ), we have no indication that clinical characteristics of included patients or other trial characteristics confounded the indirect comparisons. The use of different instruments to measure joint pain made it necessary to calculate effect sizes as a common measure of effectiveness to ensure comparability between outcomes assessed with different instruments. Poor correlation or differences in responsiveness of different instruments could be a potential threat to the validity of results. ${ }^{47}$ The scales used in the component trials of our network $(10 \mathrm{~cm}$ visual analogue scale and WOMAC pain subscales), however, were highly correlated and have comparable responsiveness. ${ }^{48}$

\section{Relation to other studies}

Several systematic reviews and meta-analyses on glucosamine and chondroitin have been published..$^{8101149-52}$ The three most recent ones were by Vlad et $\mathrm{al}^{11}$ on glucosamine, Reichenbach et $\mathrm{al}^{10}$ on chondroitin, and Lee et $\mathrm{al}^{52}$ on radiographic outcomes of both preparations. Vlad and colleagues analysed 15 trials comparing glucosamine with placebo. ${ }^{11}$ They found a pooled effect size of -0.35 (95\% confidence interval -0.56 to -0.14 ) in favour of glucosamine, but there was substantial heterogeneity. Trials with adequate concealment of allocation, industry independent trials, and trials evaluating glucosamine hydrochloride showed less beneficial effects and less pronounced heterogeneity between trials than the remainder. The authors concluded that glucosamine hydrochloride is ineffective but could not exclude the possibility of a clinically relevant effect of glucosamine sulphate. Reichenbach and colleagues found large heterogeneity among 20 chondroitin trials, which could be explained by a lack of concealment of allocation, failure to perform an intention to treat analysis, and small sample sizes. ${ }^{10}$ The initial pooled effect size of $-0.75(-0.99$ to -0.50$)$ in favour of chondroitin sulphate diminished to zero when the analysis was restricted to methodologically sound trials of adequate sample size. Both groups had analysed only one time point per trial, which was criticised. ${ }^{40}$ Lee and colleagues included six trials evaluating the effects of chondroitin or glucosamine on narrowing of joint space (four were included in our analysis and we excluded two because of small sample size). ${ }^{52}$ They found significant small to moderate protective effects. They did not, however, include the GAIT trial. ${ }^{42}$ We included methodologically superior large scale patient blinded trials in more than 200 patients in our network meta-analysis and used a statistical model that allowed the simultaneous analysis and summary of treatment effects observed at multiple time points. Addressing earlier concerns about time dependency of effects, ${ }^{40}$ quality control of preparations, ${ }^{53}$ and differences between different formulations of glucosamine,${ }^{11}$ we conclude that there is no evidence for time dependent effects, that the lack of a clinically relevant effect of these preparations is not related to a lack of quality control, and that the lack of a clinically relevant effect is also apparent for glucosamine sulphate. With the summary of multiple time points and the combination of direct comparisons within trials between preparations with indirect 


\section{WHAT IS ALREADY KNOWN ON THIS TOPIC}

Chondroitin and glucosamine have been recommended in guidelines, prescribed by genera practitioners and rheumatologists, and used by patients as over the counter medications to modify the clinical and radiological course of osteoarthritis

Results from randomised trials about the effectiveness of chondroitin and glucosamine are conflicting

\section{WHAT THIS STUDY ADDS}

Chondroitin, glucosamine, and their combination do not have a clinically relevant effect on perceived joint pain or on joint space narrowing

Estimated differences between supplements and placebo were less pronounced on average in industry independent trials, and estimated treatment effects in industry independent trials were small or absent and clinically irrelevant

evidence from other trials, these conclusions are based on considerably more high quality evidence than the previous restricted analyses of trials considered least biased by Vlad et al and Reichenbach et al. ${ }^{1011}$

\section{Implications}

We believe it unlikely that future trials will show a clinically relevant benefit of any of the evaluated preparations. Some will argue, however, that many patients included in the trials of our network were too ill in radiological terms to benefit and that their advanced radiological stage meant that the subtotal to total cartilage damage could not be influenced any more by the experimental preparations. Others will argue that many patients were not ill enough in clinical terms and that their small amount of experienced pain meant that they could not benefit from the analgesic effects of the preparations. ${ }^{54}$ To address these concerns, in addition to the trials by Clegg et al, ${ }^{13}$ Rozendaal et al, ${ }^{41}$ and McAlindon et al ${ }^{36}$ some might consider the necessity for a fourth industry independent trial, which would exclusively include patients with an experienced pain intensity at baseline of at least $4 \mathrm{~cm}$ on a $10 \mathrm{~cm}$ visual analogue scale and moderate osteoarthritis, corresponding to a Kellgren and Lawrence score of $2 .{ }^{55}$ Inclusion of 150 to 200 patients in each comparison group would yield more than $90 \%$ power to detect a minimal clinically relevant difference of $-0.9 \mathrm{~cm}$ on a $10 \mathrm{~cm}$ visual analogue scale for any of these preparations compared with placebo at a conventional two sided $\alpha$ level of $5 \%$. The trial should use coded drug packs with preparations and placebos of identical appearance and taste to conceal treatment allocation and ensure blinding of patients and care givers, carefully control and monitor analgesic cointerventions, and fully adhere to the principle of intention to treat by the inclusion of all patients in the analysis in the groups to which they were originally allocated. The evaluated preparations should have undergone thorough quality control to ensure appropriate concentrations of chondroitin and glucosamine sulphate. The industry independent randomised Long Term Evaluation of Glucosamine Sulphate Study (LEGS) will probably satisfy most of these criteria. ${ }^{56}$ It allocated 600 patients to one of four treatment arms - chondroitin sulphate, glucosamine sulphate, their combination, or matching placebo-and closed recruitment in October 2009. First results will become available at the earliest in November 2011 (M Fransen, personal communication).

\section{Conclusions}

Our findings indicate that glucosamine, chondroitin, and their combination do not result in a relevant reduction of joint pain nor affect joint space narrowing compared with placebo. Some patients, however, are convinced that these preparations are beneficial, ${ }^{57}$ which might be because of the natural course of osteoarthritis, regression to the mean, or the placebo effect. ${ }^{58} \mathrm{We}$ are confident that neither of the preparations is dangerous. Therefore, we see no harm in having patients continue these preparations as long as they perceive a benefit and cover the costs of treatment themselves. ${ }^{57}$ Coverage of costs by health authorities or health insurers for these preparations and novel prescriptions to patients who have not received other treatments should be discouraged.

We thank Bruno da Costa for helpful discussions related to minima clinically important differences and limitations of effect sizes and Malcolm Sturdy for database development and maintenance.

Contributors: SW and PJ contributed equally. PI conceived the study. PJ, ST, and SW and were responsible for conception and design of the study SW, PJ, NJW, and ST did the analysis and interpreted the analysis in collaboration with BT, EN, PMV, and SR. SW, PJ, BT, EN, SR, and ST were responsible for the acquisition of data. PJ and SW wrote the first draft of the manuscript. All authors critically revised the manuscript for important intellectual content and approved the final version of the manuscript. Pf and SR obtained public funding. PJ and PMV provided administrative, technical, and logistical support. PJ is guarantor.

Funding: The study was funded by grants from the Swiss National Science Foundation's National Research Program 53 on musculoskeletal health (PJ and SR) (No 4053-0-104762/3). PJ was a senior research fellow in the Program for Social Medicine, Preventive and Epidemiological Research funded by the Swiss National Science Foundation (grant No 3233066377). SR was a recipient of a research fellowship funded by the Swiss National Science Foundation (grant No PBBEB-115067). SW was a recipient of an individual fellowship of the Janggen-Poehn-Foundation. The study sponsor had no role in study design, data collection, data synthesis, data interpretation, writing the report, or the decision to submit the manuscript for publication. None of the authors is affiliated with or funded by any manufacturer of any of the agents evaluated in this study. Competing interests: All authors have completed the Unified Competing Interest form at www.icmje.org/coi_disclosure.pdf (available on request from the corresponding author) and declare: no support from any institution for the submitted work; no financial relationships with any institutions that might have an interest in the submitted work in the previous 3 years; no other relationships or activities that could appear to have influenced the submitted work.

Ethical approval: Not required.

Data sharing: Technical details, statistical code, and dataset available from the corresponding author.

1 Smalley WE, Ray WA, Daugherty JR, Griffin MR. Nonsteroidal antiinflammatory drugs and the incidence of hospitalizations for peptic ulcer disease in elderly persons. Am J Epidemiol 1995;141:539-45.

2 Felson DT, Lawrence RC, Hochberg MC, McAlindon T, Dieppe PA, Minor MA, et al. Osteoarthritis: new insights. Part 2: treatment approaches. Ann Intern Med 2000;133:726-37.

3 Annual nutrition industry overview. Nutrition Business / 2005;X:6-7.

4 Heller L. US glucosamine grows slow, lags global sales. 2009. www. nutraingredients-usa.com/Consumer-Trends/US-glucosaminegrows-slow-lags-global-sales.

5 Conte A, Volpi N, Palmieri L, Bahous I, Ronca G. Biochemical and pharmacokinetic aspects of oral treatment with chondroitin sulfate. Arzneimittelforschung 1995;45:918-25.

6 Ronca F, Palmieri L, Panicucci P, Ronca G. Anti-inflammatory activity of chondroitin sulfate. Osteoarthr Cartil 1998;6:14-21.

7 Persiani S, Rotini R, Trisolino G, Rovati LC, Locatelli M, Paganini D, et al. Synovial and plasma glucosamine concentrations in 
osteoarthritic patients following oral crystalline glucosamine sulphate at therapeutic dose. Osteoarthr Cartil 2007;15:764-72.

8 McAlindon TE, LaValley MP, Gulin JP, Felson DT. Glucosamine and chondroitin for treatment of osteoarthritis. A systematic quality assessment and meta-analysis. JAMA 2000;283:1469-75.

9 Jüni P, Reichenbach S, Dieppe P. Osteoarthritis: rational approach to treating the individual. Best Pract Res Clin Rheumatol 2006;20:721-40.

10 Reichenbach S, Sterchi R, Scherer M, Trelle S, Burgi E, Burgi U, et al Meta-analysis: chondroitin for osteoarthritis of the knee or hip. Ann Intern Med 2007;146:580-90.

11 Vlad SC, LaValley MP, McAlindon TE, Felson DT. Glucosamine for pain in osteoarthritis: why do trial results differ? Arthritis Rheum 2007; 56:2267-77

12 Nüesch E, Trelle S, Reichenbach S, Rutjes AW, Bürgi E, Scherer M, et al. The effects of the exclusion of patients from the analysis in randomised controlled trials: meta-epidemiological study. $B M$ J 2009;339:b3244.

13 Clegg DO, Reda DJ, Harris CL, Klein MA, O’Dell JR, Hooper MM, et al. Glucosamine, chondroitin sulfate, and the two in combination for painful knee osteoarthritis. N Engl J Med 2006;354:795-808.

14 Lumley T. Network meta-analysis for indirect treatment comparisons. Stat Med 2002;21:2313-24.

15 Stettler C, Wandel S, Allemann S, Kastrati A, Morice MC, Schomig A, et al. Outcomes associated with drug-eluting and bare-metal stents: a collaborative network meta-analysis. Lancet 2007;370:937-48.

16 Salanti G, Higgins JP, Ades AE, loannidis JP. Evaluation of networks of randomized trials. Stat Methods Med Res 2008;17:279-301.

17 Dickersin K, Scherer R, Lefebvre C. Identifying relevant studies for systematic reviews. BMJ 1994;309:1286-91.

18 Nüesch E, Trelle S, Reichenbach S, Rutjes AWS, Tschannen B, Altman DG, et al. Small study effects in meta-analyses of osteoarthritis trials: meta-epidemiological study. BMJ 2010;341:c3515.

19 Jüni P, Altman DG, Egger M. Systematic reviews in health care: assessing the quality of controlled clinical trials. $B M J$ 2001;323:42-6.

20 Smith TC, Spiegelhalter DJ, Thomas A. Bayesian approaches to random-effects meta-analysis: a comparative study. Stat Med 1995; 14:2685-99.

21 Lu G, Ades AE. Combination of direct and indirect evidence in mixed treatment comparisons. Stat Med 2004;23:3105-24.

22 Cooper NJ, Sutton AJ, Lu G, Khunti K. Mixed comparison of stroke prevention treatments in individuals with nonrheumatic atrial fibrillation. Arch Intern Med 2006;166:1269-75.

23 Cohen J. Statistical power analysis for the behavioral sciences. 2nd ed. Lawrence Erlbaum, 1988.

24 Follmann D, Elliott P, Suh I, Cutler J. Variance imputation for overviews of clinical trials with continuous response. J Clin Epidemiol 1992:45:769-73.

25 Eberle E, Ottillinger B. Clinically relevant change and clinically relevant difference in knee osteoarthritis. Osteoarthr Cartil 1999;7:502-3

26 Angst F, Aeschlimann A, Stucki G. Smallest detectable and minimal clinically important differences of rehabilitation intervention with their implications for required sample sizes using WOMAC and SF-36 quality of life measurement instruments in patients with osteoarthritis of the lower extremities. Arthritis Rheum 2001;45:384-91.

27 Angst F, Aeschlimann A, Michel BA, Stucki G. Minimal clinically important rehabilitation effects in patients with osteoarthritis of the lower extremities. J Rheumatol 2002;29:131-8.

28 Salaffi F, Stancati A, Silvestri CA, Ciapetti A, Grassi W. Minimal clinically important changes in chronic musculoskeletal pain intensity measured on a numerical rating scale. Eur J Pain 2004:8:283-91.

29 Stettler C, Allemann S, Wandel S, Kastrati A, Morice MC, Schomig A et al. Drug eluting and bare metal stents in people with and without diabetes: collaborative network meta-analysis. BMJ 2008;337:a1331.

30 Altman DG, Bland JM. Interaction revisited: the difference between two estimates. BMJ 2003;326:219.

31 Lu G, Ades AE. Assessing evidence inconsistency in mixed treatment comparisons. J Am Stat Assoc 2006;101:447-59.

32 Brooks S, Gelman A. Alternative methods for monitoring convergence of iterative simulations. J Comput Graph Stat 1998;7:434-55.

33 Noack W, Fischer M, Forster KK, Rovati LC, Setnikar I. Glucosamine sulfate in osteoarthritis of the knee. Osteoarthr Cartil 1994;2:51-9.

34 Reginster JY, Deroisy R, Rovati LC, Lee RL, Lejeune E, Bruyere O, et al. Long-term effects of glucosamine sulphate on osteoarthritis progression: a randomised, placebo-controlled clinical trial. Lancet 2001;357:251-6.

35 Pavelka K, Gatterova J, Olejarova M, Machacek S, Giacovelli G, Rovati LC. Glucosamine sulfate use and delay of progression of knee osteoarthritis: a 3-year, randomized, placebo-controlled, doubleblind study. Arch Intern Med 2002;162:2113-23.

36 McAlindon T, Formica M, LaValley M, Lehmer M, Kabbara K. Effectiveness of glucosamine for symptoms of knee osteoarthritis: results from an internet-based randomized double-blind controlled trial. Am / Med 2004;117:643-9.

37 Michel BA, Stucki G, Frey D, De Vathaire F, Vignon E, Bruehlmann P, et al. Chondroitins 4 and 6 sulfate in osteoarthritis of the knee: a randomized, controlled trial. Arthritis Rheum 2005;52:779-86.

38 Mazières B, Hucher M, Zaim M, Garnero P. Effect of chondroitin sulphate in symptomatic knee osteoarthritis: a multicentre, randomised, double-blind, placebo-controlled study. Ann Rheum Dis 2007;66:639-45.

39 Herrero-Beaumont G, Ivorra JA, Del Carmen Trabado M, Blanco FJ, Benito P, Martin-Mola E, et al. Glucosamine sulfate in the treatment of knee osteoarthritis symptoms: a randomized, double-blind, placebo-controlled study using acetaminophen as a side comparator. Arthritis Rheum 2007;56:555-67.

40 Helg AG. How solid are the results of the meta-analysis by Reichenbach et al and its conclusions? Ann Intern Med 2009. www.annals.org/content/146/8/580.abstract/ reply\#annintmed_el_44993.

41 Rozendaal RM, Koes BW, van Osch GJ, Uitterlinden EJ, Garling EH, Willemsen SP, et al. Effect of glucosamine sulfate on hip osteoarthritis: a randomized trial. Ann Intern Med 2008;148:268-77.

42 Sawitzke AD, Shi H, Finco MF, Dunlop DD, Bingham CO 3rd, Harris CL, et al. The effect of glucosamine and/or chondroitin sulfate on the progression of knee osteoarthritis: a report from the glucosamine/ chondroitin arthritis intervention trial. Arthritis Rheum 2008;58:3183-91.

43 Kahan A, Uebelhart D, De Vathaire F, Delmas PD, Reginster JY. Long term effects of chondroitins 4 and 6 sulfate on knee osteoarthritis: the study on osteoarthritis progression prevention, a two-year, randomized, double-blind, placebo-controlled trial. Arthritis Rheum 2009;60:524-33.

44 Egger M, Jüni P, Bartlett C, Holenstein F, Sterne J. How important are comprehensive literature searches and the assessment of trial quality in systematic reviews? Empirical study. Health Technol Assess 2003;7:1-76.

45 Egger M, Smith GD. Principles of and procedures for systematic reviews. In: Egger M, Smith GD, Altman DG, eds. Systematic reviews in health care: meta-analyis in context. BMJ Publishing, 2001:23-42.

46 Wood L, Egger M, Gluud LL, Schulz KF, Jüni P, Altman DG, et al. Empirical evidence of bias in treatment effect estimates in controlled trials with different interventions and outcomes: metaepidemiological study. BMJ 2008;336:601-5.

47 Puhan MA, Soesilo I, Guyatt GH, Schunemann HJ. Combining scores from different patient reported outcome measures in meta-analyses: when is it justified? Health Qual Life Outcomes 2006;4:94.

48 Gentelle-Bonnassies S, Le Claire P, Mezieres M, Ayral X, Dougados M. Comparison of the responsiveness of symptomatic outcome measures in knee osteoarthritis. Arthritis Care Res 2000;13:280-5.

49 Towheed TE, Maxwell L, Anastassiades TP, Shea B, Houpt J, Robinson V, et al. Glucosamine therapy for treating osteoarthritis. Cochrane Database Syst Rev 2005;2:CD002946.

50 Poolsup N, Suthisisang C, Channark P, Kittikulsuth W. Glucosamin long-term treatment and the progression of knee osteoarthritis: systematic review of randomized controlled trials. Ann Pharmacother 2005;39:1080-7.

51 Bruyere O, Burlet N, Delmas PD, Rizzoli R, Cooper C, Reginster JY. Evaluation of symptomatic slow-acting drugs in osteoarthritis using the GRADE system. BMC Musculoskelet Disord 2008;9:165.

52 Lee YH, Woo JH, Choi SJ, Ji JD, Song GG. Effect of glucosamine or chondroitin sulfate on the osteoarthritis progression: a metaanalysis. Rheumatol Int 2010;30:357-63.

53 Reginster JY. The efficacy of glucosamine sulfate in osteoarthritis: financial and nonfinancial conflict of interest. Arthritis Rheum 2007;56:2105-10.

54 Fortin PR, Stucki G, Katz IN. Measuring relevant change: an emerging challenge in rheumatologic clinical trials. Arthritis Rheum 1995;38:1027-30.

55 Kellgren JH, Lawrence JS. Radiological assessment of osteo-arthrosis. Ann Rheum Dis 1957;16:494-502.

56 Fransen M, Day R, Bridges-Webb C, Edmonds J, Norton R, Woodward $\mathrm{M}$, et al. The long-term evaluation of glucosamine sulphate study (LEGS). 2009. http://clinicaltrials.gov/ct2/show/ NCT00513422.

57 Felson DT. Chondroitin for pain in osteoarthritis. Ann Intern Med 2007;146:611-2.

58 Krogsboll LT, Hrobjartsson A, Gotzsche PC. Spontaneous improvement in randomised clinical trials: meta-analysis of threearmed trials comparing no treatment, placebo and active intervention. BMC Med Res Methodol 2009:9:1.

Accepted: 5 July 2010 